\title{
“Association between Feelings about Competition and Self-Reported Happiness: Do Racial Differences Matter?" Evidence from the World Value Surveys
}

\author{
Juan Barrios \\ Universidad ORT Uruguay, Montevideo, Uruguay \\ Email: barrios@ort.edu.uy \\ Received 6 April 2016; accepted 23 May 2016; published 26 May 2016 \\ Copyright (C) 2016 by author and Scientific Research Publishing Inc. \\ This work is licensed under the Creative Commons Attribution International License (CC BY). \\ http://creativecommons.org/licenses/by/4.0/ \\ (c) (i) Open Access
}

\begin{abstract}
Drawing on individual data from the World Values Surveys, this paper estimates the importance of racial differences in the relation between individual feelings about competition and self-reported happiness. Racial or ethnic characteristics are split as Asians, Blacks and Whites. In general, people who think competition is good are associated to the same (high) level of happiness as do people who think competition is harmful. Blacks, however, appear to shy away from competition probably because they are not the winners in the competitive process of capitalism. Results among blacks within different countries show similar patterns. These findings are different than and complement previous research which shows a positive or negative relation between competition and well-being. The paper improves over previous research in that it approximates competitive environment by using individual-level measures and considers the relevance of cultural differences. Instrumental variable analysis suggests that there may be a relation of causality stemming from competition to happiness. The paper conjectures about the reasons why individuals who find competition as harmful report higher levels of happiness but do not attempt to establish causality directions.
\end{abstract}

\section{Keywords}

Subjective Well-Being, Happiness, Utility, Competition, Econometrics, World Values Surveys, Culture

\section{Introduction}

The association between competition and well-being has been a debatable issue for quite a long time. Mainstream

How to cite this paper: Barrios, J. (2016) "Association between Feelings about Competition and Self-Reported Happiness: Do Racial Differences Matter?" Evidence from the World Value Surveys. Open Journal of Social Sciences, 4, 225-242. 
Economic theory and most Professional Economists postulate that competition drives the forces of development. Competition, relative to non-competitive structures such as monopoly and oligopoly, creates positive incentives for producers to boost technological progress, improve efficiency and optimize resource allocation, thus improving social welfare. Competition should improve consumers' wellbeing by putting downward pressure on prices because consumers, for equal quality, should have more opportunities to buy cheaper products, kicking inefficient suppliers out of the market.

In assessing the wellbeing effects of economic choices, economists have been traditionally led by the principle of revealed preference, by which if we observe an individual choosing consumption bundle $A$ over consumption bundle $\mathrm{B}$, he does so because he prefers bundle A over bundle B and in choosing bundle A over bundle $\mathrm{B}$, presumably, the individual will maximize his wellbeing. But this is a logical conclusion derived from appropriate assumptions and it is by no means clear if it constitutes a measure of individual wellbeing.

The theoretical arguments developed by mainstream economists about the benefits of market competition are strong and they seem to have percolated into the minds and souls of other social agents, such as politicians, but also appear to have strong influence on the general public.

In sum, most economists have developed theoretical arguments which show competition as favoring efficient outcomes, while they have also developed logical reasoning and opinions which "explain" why competitive capitalism improves individual wellbeing.

On the other hand, the study of happiness, which many researchers use as an approximation to individual wellbeing, originally a domain of psychology, has been making its way into the field of economics over the past decades as researchers have used survey and experimental data to delve into the nature of the association between well being and political and economic institutions, although some of these studies use self-reported life satisfaction instead of self-reported happiness as their measure of wellbeing [1].

This paper contributes to the literature on the relation between economic institutions and happiness by focusing on one specific economic institution: market competition. Furthermore, this paper investigates if there are differences in the relation of competition and happiness which may be driven by racial, ethnic or cultural differences.

The study of the effect of ethnic differences on economic outcomes has increased in the last few years. Some authors have identified ethnicity as a characterization of culture. For example, in a widely cited study, [2] defines culture as those "customary beliefs and values that ethnic, religious, and social groups transmit fairly unchanged from generation to generation". This paper analyzes whether the relation between competition and happiness is the same for individuals with different cultural (ethnic) backgrounds.

This investigation uses self-reported opinions about competition derived from the World Value Surveys (WVS) [3]. Based on the information collected so far, this is the first paper to use the opinions of individuals about competition rather than using quantitative aggregate measures such as the degree of openness of an economy or the volume of capital inflows and outflows. As a consequence, the measure of competition used presently is an individual measure rather than an aggregate measure which may prove more useful to draw appropriate conclusions with respect to individual behavior and causality relations.

Data collected by the WVS also includes information about the ethnicity of the respondent which is used to gauge into the importance of ethnicity differences. Competition may be regarded differently by, say, citizens of developed countries relative to citizens of less developed countries, or by Asian individuals relative to Whites and Blacks, for example. This is probably the first paper attempting to explore this issue directly using data collected at the individual level.

As suggested above, individual wellbeing has proved difficult to measure in empirical studies probably, in part, due to difficulties in determining what the term represents, conceptually ${ }^{1}$ [4] [5]. Accordingly, researchers have approximated individual wellbeing by collecting survey information on self-reported individual satisfaction and individual happiness (e.g. the World Value Surveys) and by running experimental games to analyze behavioral outcomes ${ }^{2}$.

Empirical studies which assess the positive relationship between market competition and individual wellbeing postulated mainly by mainstream economists find this relationship questionable, particularly studies of behavioral

${ }^{1}$ See e.g. Diener (1984) for a discussion of theoretical and methodological issues related to the concept of wellbeing. For example Ryff and Keys (1995, cited in Triandis (2000)) argue that wellbeing arises from the combination of six aspects: self-acceptance, positive relation with others, autonomy, environmental mastery, purpose in life and personal growth.

${ }^{2}$ Happiness and life satisfaction do not represent the same thing (see below), for example, Campbell et al. (1997) (cited in Triandis (2000)) find that while American young individuals feel happier than their older counterparts, the reverse is true for how satisfied they feel about life. 
economics, sociology, psychology and political science.

Empirical Psychological studies of children behavior, cited in Kohn [6] found that children learn better when they are exposed to cooperative environments (65\% of the cases) with respect to competitive environments (7\%). Other studies also cited in Kohn test for creativity of children and find that those children who were competing for prizes produced less creative collages than those who were not competing for prizes.

More closely related to Economics, Brandts et al. [7] use laboratory experiments in which participants play a repeated social dilemma game (played by a fix group of subjects ${ }^{3}$ with fixed roles) to study the effects of competition on efficiency and material wellbeing, subjective wellbeing and individual's disposition towards others, Liebrand $^{4}[8]$.

Subjective wellbeing and disposition towards others are obtained by surveying the participant's emotions before and after the experiments. Brandts et al. consider specifically the fact that preferences and tastes are no independent of the institutional environment and that economic interactions are contractually incomplete. In an environment with incomplete contracts, they find that the competitive scenario neither leads to an increase in efficiency not it leads to material gains to the short side of the transaction relative to the non-competitive scenario. Further, competition harms the subjective wellbeing of the long side. Only the subjective wellbeing of the short side to the transaction is improved. The short side to the transaction is significantly happier than the other two competing parties on the long side and is also happier than any of the two parties in the non-competitive game. Moreover, competition appears to adversely affect disposition towards those on the long side of the transaction.

Although Brandts et al. nicely capture the rivalry aspects of competition [9], the sample they use appears to be non-representative: they collected data on 153 subjects and they do not specify in which way they selected the individuals ${ }^{5}$.

More related to the spirit of this paper, Fischer [10] uses data from the third and fourth waves of the WVS ${ }^{6}$ and other sources and finds that market competition increases happiness inequality by aggravating the harmful effects on inequality of differences in economic power ${ }^{7}$, that is, competition makes those with greater bargaining power happier relative to those with less bargaining power.

Fischer segregates the happiness-effect of competition in three parts: 1) the financial gains obtained through competition, 2) the intensity of market transactions, and 3) the degree of bargaining power of the short side, that is, the happiness-empowering effect of having the power of excluding others on the long side from the economic transactions thus augmenting the latters' economic insecurity. The third part may increase or decrease overall happiness depending on the magnitude of the effect on the short side relative to the long side of the transaction. Fischer hypothesis is that market competition re-enforces the bargaining power effect for participants' subjective wellbeing (her Hypothesis 1).

Her dependent variable arises from individuals' answers to the question: "All things considered, how satisfied are you with your life as a whole these days?”. Persons answering this question have 10 options, the first being "dissatisfied", the tenth being "very satisfied". In addition, Fischer approximates market competition by using the KOF index of economic globalization, which measures the integration of a national economy in the world market. Fischer hypothesis is that the degree of market competition in a country can be approximated by the degree of economic integration of that country in the world economy ${ }^{8}$. As such, it constitutes a national, aggregated data, which does not represent a measure of individual behavior or opinion ${ }^{9}$.

Fischer does not use self-reported happiness as her dependent variable but self-reported satisfaction. Although both are positively correlated ${ }^{10}$, they probably do not mean the same thing. Also, since her measure of market competition is aggregated at the country level at two different points in time, in order to obtain the same number of observations at the individual level, she needs to impute that same measures to all individuals in that country

\footnotetext{
${ }^{3}$ The game is played by two players in the Non-Competitive environment and by three players in the Competitive environment. In the latter, one party has to choose with who of the other two players she will play, thus creating a competitive condition. Games are repeated over 30 rounds.

${ }^{4}$ Subjective wellbeing is measured by computing self-reported hedonic states experienced by the participants, while disposition towards others is measured using a variant of a social value orientation test (Liebrand, 1984).

${ }^{5}$ Since the experiments were run at the University of Amsterdam, the sample may well consist of university students.

${ }^{6}$ The surveys cover more than 60 countries and collect information on some 80.000 individuals.

${ }^{7}$ Economic or bargaining power is measured by the absolute self-reported income level of each individual.

${ }^{8}$ Since Fischer is interested in the effect of an individual bargaining position on happiness inequality, she interacts her self-reported satisfaction with self-reported (absolute) income level, also from the WVS.

${ }^{9}$ Nevertheless, since the KOF index may be correlated with economic growth or income inequality, Fischer uses the predicted residuals of a regression of the KOF index on GDP.

${ }^{10}$ Their pairwise correlation is low. 0.0475 .
} 
at that moment of time. This may not represent a true measure of market competition, at least does not represents what each individual thinks about competition and it would be probably better to treat it as a country fixed effect.

On the other hand, Fischer does not show that being more open to international markets must be necessarily associated with increased competition, which may be true for small economies, but not necessarily for larger ones: in fact, more protection may increase the actual number of local producers competing in the market. Finally, to assess the effect of market competition through bargaining power, she also imputes the (country) index of market competition to each individual income (which approximates each individual's bargaining power).

The effect of different cultural traits on happiness has been studied by psychologists, sociologists and economists, to say the least. Traditionally, the difference between individualistic (e.g. capitalistic) and collectivistic countries has been assessed [11] [12]. In addition, drawing on data collected from individuals of three tribes ${ }^{11}$, Biswass Diener et al. [13] find significant cultural effects on happiness. Guiso et al. use ethnic background as an instrument for cultural differences to analyze the effect of culture on individual preferences and economic outcomes.

Although related to the above literature, this paper attempts to determine the effect of views about competition on happiness, across different ethnic backgrounds. In other words, this paper focuses not on the relation between ethnic backgrounds and happiness but on the relation between competition and happiness across different ethnic groups. As of available information, this is the first paper in attempting to do such an analysis.

In sum, this paper analyzes the association between one of the most respectable institutions of capitalism, competition, and feelings of happiness, and studies if this relation varies across ethnic or racial groups using data from the 2005 wave of the World Value Surveys (WVS). One important issue relates to causality. We do not attempt to establish a causal relation between competition and happiness. Happier people may be more inclined to appreciate competition more than less happy people. On the other hand, a person who dislikes competition and its consequences may feel less happy because of that fact. In other words, causality me ran both ways. Another important issue relates to the definition of ethnicity or "racial". One may question the approach taken here and refinements to our approach are certainly welcome, but we feel it is an important first step to investigate if different types of individuals across countries associate subjective views of competition and happiness in the same way. More on this below

Using the WVS improves over the Brandts et al. study in that the WVS build on representative samples and avoids the problem of self-selection typical of experimental studies. It also improves over the Fischer study in that the present paper considers a subjective opinion about whether an individual thinks market competition is good or harmful (see below) which, as argued above, constitutes an individual measure and it may also be considered an ex-ante opinion, independent of the actual competitive environment derived from any aggregated approximation to competition, such as the KOF globalization index [14].

Last but not least, competition means different things for different scholars. Mainstream economists conceptualize competition as an "end-state": competitive markets should achieve efficient social outcomes. The opinions surveyed in the WVS, however, may not coincide with the economist's vision of competition in that it may be representing a "process" [15] in which firms attempt to maximize their stake of the market, sometimes achieving a zero-sum outcome: what one firm gains, other firm looses. That process may lead to satisfactory outcomes, e.g. lower prices, but may also lead to higher unemployment, lower quality products, or what is commonly denominated a "race to the bottom". Under this second view competition may drive firms to undertaking unfair, unjust and environmentally damaging strategies in order to get a larger share of the market ${ }^{12}$, thus a bad thing [16]. This process-view of competition, expressed by the answers collected in the WVS, is the view of what ordinary people do understand by competition (more below) and it is what is implicitly considered in this paper.

If people view competition as mainstream economists do, a direct and positive relation between their subjective view of competition and self-assessed happiness should obtain. On the contrary, if the process view of competition prevails, mixed results are possible, that is, the relation between competition and happiness could be non-linear, for example. One can conjecture that there may be a "competition threshold", beyond which, negative views of competition may actually be positive for wellbeing.

Section 2 describes the data used in the paper. Section 3 specifies the intuition behind the econometric model

\footnotetext{
${ }^{11}$ The tribes were: the Kenyan Maasai, the United States Amish, and the Greenlandic Inughuit.

${ }^{12}$ These strategies may include deceiving costumers through advertising, for example. Some critics of corporate global capitalism have also argued that multinationals foster environmentally unsustainable growth strategies, which harm us all.
} 
employed and describes such model. Section 4 shows the results for each of the ethnic groups and checks for robustness. Section 5 concludes and discusses results, limitations of this study, and future research.

\section{Method}

\subsection{Data}

\subsubsection{Participants}

The data used in this work was collected in the fourth wave (2005-2008) of the World Values Surveys (WVS). The WVS periodically collect self-reported opinions and beliefs about cultural values of representative samples of individuals over dozens of countries around the world. The fourth wave collected the opinions of 67,268 individuals from 56 countries. Among other things, individuals are asked about their perceptions of life, which includes self-assessments of happiness. They are also asked about politics and society in general, which includes a question about what they think about competition. The surveys also collect socio-demographic characteristics of each individual which includes a question relative to the ethnic group of the respondent

\subsubsection{Variables}

The dependent variable (happiness) is built by considering the WVS question about the individual's state of happiness. Individuals are asked to answer the following question: "Taking all things together, would you say that you are 1) very happy, 2) quite happy, 3) Not very happy, 4) Not at all happy?.”, thus a categorical variable which takes four values. This variable is ordered in the sense that each category represents a level of happiness that can be compared with the preceding and following category: when the individual's answer falls in category 3 , such person is less happy than some other individual whose answer fell in category 2 but happier than other individual whose answer fell in the following category 4.

Competitive capitalism or market competition is approximated by computing the feeling individuals express about competition. Specifically, individuals are asked the following question: "How would you place your views on this scale? 1 means you agree completely with the statement on the left; 10 means you agree completely with the statement on the right; and if your views fall somewhere in between, you can choose any number in between. Sentences: Competition is good. It stimulates people to work hard and develop new ideas vs Competition is harmful. It brings the worst in people".

Briefly, should a person chooses option 1 it would mean she believes competition is a good thing, while if she chooses option 10 it would mean she believes competition is harmful. In sum, competition is also a categorical variable that takes 10 values, from 1 (good) to 10 (harmful). Moving downwards from the first category, each subsequent category represents less sympathy towards competition.

To take account of cultural differences the data is segregated according to what is defined here as a different culture: ethnic differences ${ }^{13}$. To take account of specific ethnic differences, the WVS data is divided in three samples of different individuals: Asians, Whites, and Blacks. These groups account for almost $63 \%$ of the individuals surveyed in the WVS and represent a fairly accurate description of three different cultures. As a first glance to potential differences between ethnic groups, Table 1 decomposes self-reported happiness for Asians, Blacks and Whites.

Although Whites and Asians appear to be similar with respect to their feelings about happiness, this is not the case for Black individuals: more than $22 \%$ of them declare not to be happy compared to $16 \%$ of whites and Asians.

Since opinions about competition are segregated into 10 categories, it is a bit more complicated to draw differences, if any. Nevertheless, Table 2 shows that Blacks are more inclined than Asians and Whites to answer that competition is good as are also more inclined to think that competition is harmful.

The fourth wave of the WVS also collects socio-demographic data of each individual which are used as control variables. These include whether the respondent is female or male, his/her years of age, self-reported education level, employment status, income level and social class. Education is a categorical variable ranging from level 1 (no formal education) to level 9 (university education with degree), level 1 being the omitted (reference) category. As previous empirical studies show, more educated individuals tend to be happier [17].

\footnotetext{
${ }^{13}$ At least to issues are relevant here. First, there are also differences within Blacks, Whites and Asians. Moreover, different countries apply different criteria to define the meaning of, say, "black". The first issue could be analyzed as a natural extension to this work. The second issue is (partially) addressed in this paper by the inclusion of country fixed effects.
} 
Table 1. Self reported happiness ethnic groups.

\begin{tabular}{ccccc}
\hline Ethnicity & Very Happy & Quite Happy & Not so Happy & Not at all Happy \\
\hline Asians & $22.7 \%$ & $61.5 \%$ & $13.2 \%$ & $2.5 \%$ \\
Blacks & $29.5 \%$ & $48.1 \%$ & $19.0 \%$ & $3.5 \%$ \\
Whites & $29.2 \%$ & $54.9 \%$ & $13.5 \%$ & $2.4 \%$ \\
\hline
\end{tabular}

Table 2. Feelings about competition different ethnic groups.

\begin{tabular}{lcccccccccc}
\hline Ethnic & Competition is good & $\mathbf{2}$ & $\mathbf{3}$ & $\mathbf{4}$ & $\mathbf{5}$ & $\mathbf{6}$ & $\mathbf{7}$ & $\mathbf{8}$ & $\mathbf{9}$ & Competition is Harmful \\
\hline Asians & $16 \%$ & $15 \%$ & $19 \%$ & $13 \%$ & $17 \%$ & $7 \%$ & $4 \%$ & $4 \%$ & $2 \%$ & $2 \%$ \\
Black & $28 \%$ & $13 \%$ & $11 \%$ & $10 \%$ & $13 \%$ & $7 \%$ & $4 \%$ & $5 \%$ & $3 \%$ & $6 \%$ \\
White & $20 \%$ & $13 \%$ & $15 \%$ & $13 \%$ & $16 \%$ & $7 \%$ & $5 \%$ & $5 \%$ & $3 \%$ & $4 \%$ \\
\hline
\end{tabular}

Employment status is a not-ordered categorical variable since not all the categories imply that the next (or previous) category is better (or worse). The respondent is given 9 alternatives to answer with respect to her employment status according to Table 3 .

There is no ex-ante reason to believe that a house wife would be more or less happy than a full time employee or a student. But if we assume that having a job (or else, doing something relative to being unemployed) makes a person happier than not having a job, which appears reasonable, there would be reasons to believe that the level of happiness of all categories would be higher than that reported by the unemployed, as studies on the relation of unemployment and happiness suggest [18]. Category 7 (Unemployed) is used as the reference category, accordingly.

Self-reported income is measured using deciles, the first representing the lowest income (which is the reference category). Within a country, evidence shows that higher income individuals are happier. International comparisons, however, have shown that the average level of happiness does not change much with respect to the average level of income per person, which has been delved the Easterlin Paradox [19]. Finally individuals report as belonging to one of five social classes, the first being the upper class (the reference category in this paper). The descriptive statistics of these control variables are shown in Table 4.

\subsection{The Model}

Happiness is a categorical variable that takes 4 values as described above. Individuals answer according to how happy they regard themselves. In other words, responses are ordered: here a person selecting option 1 is happier than a person who selects option 2 and so on. As Train [20] explains, one way to conceptualize this process of decision is to think about some level of opinion or utility associated with the answer given. That is, a person whose (unobserved) opinion about happiness is above some level $Z_{1}$ will choose to answer "very happy” and a person whose opinion about happiness is below $Z_{1}$ but above $Z_{2}$ will choose to answer "quite happy", those whose opinions are below $Z_{2}$ and above cutoff point $Z_{3}$ will answer "not very happy”, while those with opinions below $Z_{3}$ will respond "not at all happy".

This unobserved level of opinion or utility associated with happiness is affected by observed and unobserved variables as specified next. Assuming a specific distribution for the unobserved variables (e.g. logistic), the probability of each answer for the level of happiness can be determined. The estimated parameters give the impact of the explanatory variables on self-reported levels of happiness. If the model uses the logistic distribution for the unobserved variables, this model is called ordered logit, and it is the one used in this paper.

Following the intuition outlined above, the econometric model specifies individual's “i” happiness (Happy $y_{i}$ as a function of how individual " $i$ " feels about competition $\left(\right.$ Comp $\left._{i}\right)$, other observed socio-demographic variables $\left(X_{i}\right)$, country fixed effects and other unobserved variables. This relation can be expressed as follows ${ }^{14}$ :

$$
\text { Happy }_{i}=\alpha \text { Comp }_{i}+\beta X_{i}+\varepsilon_{i}
$$

\footnotetext{
${ }^{14}$ I consider the same equation for each of the three samples mentioned above. Note that higher numbers represent worse feelings about competition and lower levels of happiness.
} 
Table 3. Employment categories.

\begin{tabular}{cc}
\hline Category & Status \\
\hline 1 & Full time employee (more than 30 hours per week) \\
2 & Part time employee \\
3 & Self employed \\
4 & Retired/pensioned \\
5 & House wife not otherwise employed \\
6 & Student \\
7 & Unemployed \\
8 & Other \\
\hline
\end{tabular}

Table 4. Descriptive statistics.

\begin{tabular}{|c|c|c|c|c|c|c|}
\hline Variable & Description & Obs & Mean & Std. Dev. & Min & Max \\
\hline Happiness & $\begin{array}{l}\text { "Taking all things together, would you say that you are 1) } \\
\text { very happy, 2) quite happy, 3) Not very happy, 4) Not at all } \\
\text { happy?. }\end{array}$ & 6610 & 1.9134 & 0.72683 & 11 & 4 \\
\hline Competition & $\begin{array}{l}\text { "How would you place your views on this scale? } 1 \text { means } \\
\text { you agree completely with the statement on the left; } 10 \\
\text { means you agree completely with the statement on the right; } \\
\text { and if your views fall somewhere in between, you can } \\
\text { choose any number in between. Sentences: Competition is } \\
\text { good. It stimulates people to work hard and develop new } \\
\text { ideas vs Competition is harmful. It brings the worst in people }\end{array}$ & 64,210 & 3.7532 & 2.4806 & 11 & 110 \\
\hline Competition 2 & & 64,210 & 20.240 & 24.265 & 11 & 1100 \\
\hline Female & $1=$ male $; 2=$ female & 67,222 & 1.5217 & 0.49952 & 10 & 1 \\
\hline Age & Years & 67,050 & 41.777 & 16.544 & 15 & 98 \\
\hline Education & $\begin{array}{l}\text { 1) no formal education, 2) incomplete primary, 3) complete } \\
\text { primary; 4) incomplete technical secondary; 5) complete } \\
\text { technical secondary; 6) incomplete university secondary; } \\
\text { 7) complete university secondary; 8) some university; 9) } \\
\text { university with degree }\end{array}$ & 66,794 & 5.1705 & 2.5093 & 1 & 9 \\
\hline Employment & $\begin{array}{l}\text { 1) full time; 2) part time; 3) self-employed; 4) retired/ } \\
\text { pensioned; 5) House wife; 6) Student; 7) Unemployed; 8) } \\
\text { Other }\end{array}$ & 65,018 & 3.4319 & 2.2008 & 1 & 8 \\
\hline Social Class & $\begin{array}{l}\text { 1) upper; 2) upper middle; 3) lower middle; 4) working; 5) } \\
\text { lower }\end{array}$ & 61,615 & 3.3763 & 0.99982 & 1 & 5 \\
\hline Income & $\begin{array}{l}\text { 1) lower; 2) } 2^{\text {nd }} ; \text { 3) } 3^{\text {rd }} \text {;) } 4^{\text {th }} \text {; 5) } 5^{\text {th }} \text {; 6) } 6^{\text {th }} \text {;) } 7^{\text {th }} \text {; 8) } 8^{\text {th }} \text {; } \\
\text { 9) } 9^{\text {th }} \text {;0) upper }\end{array}$ & 60,541 & 4.5979 & 2.2781 & 1 & 10 \\
\hline
\end{tabular}

where $\varepsilon_{i}$ is an individual-specific error term which is assumed to be distributed logistic.

Since the dependent variable is categorical, OLS results may be biased and inefficient. Nevertheless OLS are run first for the whole sample to gauge for any non-linear relation between competition and happiness. Following the OLS regression, order logit technique is applied to take account of the nature of the variables involved.

To take differences in ethnicity in consideration three different regressions are run where the competitioneffect on happiness for the three different ethnic groups mentioned above is analyzed.

Since the results of this type of regressions are difficult to evaluate, marginal effects of competition on the probability of being very happy (value $=1$ ) are computed, which also will help in the evaluation of nonlinearities. 
Control variables include self-reported income, social class, educational level, gender, age and country fixed effects for each of the samples as outlined in the preceding section and described in Table 4.

\section{Data Analysis}

\subsection{Results}

\subsubsection{OLS Results}

The results from the OLS regression are shown in Table 5. Robust standard errors are shown. Results show a positive but nonlinear relation between competition and happiness. Although individuals who think competition is relatively good are associated with higher self-reported happiness, the relationship appears to have a minimum $^{15}$, as shown by the negative coefficient of the square of competition.

Figure 1 and Figure 2 show some support for this preliminary result. These graphs plot the predicted levels of happiness (vertical axis) against the opinions about competition (horizontal axis). Those who feel competition is good are, on average, as happy as those who feel competition is harmful. The inverted-U form of the relationship suggests that as individuals feel competition is less beneficial, they also regard themselves as less happy. But this goes up to a point beyond which the relationship becomes negative: happier persons are associated with the view that competition as more harmful than beneficial.

\subsubsection{Ordered Logit Regressions}

Three different regressions are run, each corresponding to Asians, Whites, and Blacks, respectively. Results for the three different ethnic groups are shown in Tables $6-9^{16}$. Results show that feelings about competition have different effects on happiness for different ethnic groups.

Country fixed effects are considered but not reported. Country fixed effects comprise variables such as the competitive environment of a country or its institutional structure. In this sense, the coefficients of competition (the $\alpha$ 's) reflect the individual effect of feelings about competition on self-reported happiness.

Table 6 shows the results of the effect of feelings about competition on self-reported happiness for each ethnic group. Since the omitted category is Category 1 (i.e. those individuals who think competition is good), the regression coefficients reflect the effect of competition on happiness relative to those individuals. Since all coefficients are positive, the first conclusion is that individuals who think competition is increasingly harmful tend to report lower levels of happiness relative to category 1.

A second observation is that competition does not have any statistical effect on self-reported happiness for individuals who think competition is harmful (categories 9 and 10) with respect to those who think competition is good. Moreover, in the case of Black persons, this result applies starting for individuals of Category 5 downwards. These findings verify the initial intuition of a non-linear relation between feelings about competition and

Table 5. Competition and happiness OLS regression dependent variable: Happiness.

\begin{tabular}{ccccccc}
\hline Happiness & Coef. & Std. Err. & $\mathrm{T}$ & $\mathrm{P}>\mathrm{t}$ & [95\% Conf. & Interval] \\
\hline Competition & 0.034 & 0.004 & 7.59 & 0.000 & 0.025 & 0.0433 \\
Competition square & -0.003 & 0.0004 & -6.84 & 0.000 & -0.004 & -0.002 \\
Female & -0.016 & 0.006 & -2.69 & 0.007 & -0.028 & -0.004 \\
Age & 0.002 & 0.0001 & 10.59 & 0.000 & 0.001 & 0.002 \\
Education & 0.001 & 0.001 & 1.43 & 0.154 & -0.0007 & 0.004 \\
Employment & 0.009 & 0.001 & 6.37 & 0.000 & 0.006 & 0.012 \\
Social Class & 0.086 & 0.003 & 22.50 & 0.000 & 0.079 & 0.094 \\
Income level & -0.047 & 0.001 & -28.98 & 0.000 & -0.050 & -0.044 \\
_cons & 1.682 & 0.027 & 61.58 & 0.000 & 1.629 & 1.736
\end{tabular}

Observations: 52.699; R2: 0.06; F $(8,52690)=378.38$; Prob $>$ F $=0.0000$.

\footnotetext{
${ }^{15}$ Note that higher numbers represent worse feelings about competition and lower levels of happiness.

${ }^{16}$ Tables 6-9 show the results for all dependent variables. Country fixed effects are included in the regression but are not reported.
} 
Table 6. Ologit regression effect of competition on happiness per ethnic group dependent variable: Happiness.

\begin{tabular}{|c|c|c|c|}
\hline VARIABLES & Asians & Blacks & Whites \\
\hline \multirow[t]{2}{*}{ Competition 2} & $0.404^{* * *}$ & $0.332^{* * *}$ & 0.039 \\
\hline & $(0.109)$ & $(0.083)$ & $(0.063)$ \\
\hline \multirow[t]{2}{*}{ Competition 3} & $0.537^{* * *}$ & $0.257^{* * *}$ & $0.324^{* * *}$ \\
\hline & $(0.106)$ & $(0.085)$ & $(0.06)$ \\
\hline \multirow[t]{2}{*}{ Competition 4} & $0.444^{* * *}$ & $0.290^{* * *}$ & $0.364^{* * *}$ \\
\hline & $(0.112)$ & $(0.085)$ & $(0.063)$ \\
\hline \multirow[t]{2}{*}{ Competition 5} & $0.443^{* * *}$ & $0.148^{*}$ & $0.229^{* * *}$ \\
\hline & $(0.113)$ & $(0.079)$ & $(0.061)$ \\
\hline \multirow[t]{2}{*}{ Competition 6} & $0.627^{* * *}$ & 0.071 & $0.254^{* * *}$ \\
\hline & $(0.136)$ & $(0.099)$ & $(0.077)$ \\
\hline \multirow[t]{2}{*}{ Competition 7} & $0.526^{* * *}$ & 0.118 & $0.170^{*}$ \\
\hline & $(0.184)$ & $(0.11)$ & $(0.087)$ \\
\hline \multirow[t]{2}{*}{ Competition 8} & $0.563^{* * *}$ & 0.038 & $0.341^{* * *}$ \\
\hline & $(0.183)$ & $(0.118)$ & $(0.092)$ \\
\hline \multirow[t]{2}{*}{ Competition 9} & 0.345 & 0.152 & 0.162 \\
\hline & $(0.26)$ & $(0.136)$ & $(0.123)$ \\
\hline \multirow[t]{2}{*}{ Competiitoin 10} & 0.228 & -0.011 & 0.027 \\
\hline & $(0.256)$ & $(0.125)$ & $(0.111)$ \\
\hline
\end{tabular}

Table 7. Ologit regression controls: Sex, age and education on happiness per ethnic group dependent variable: Happiness.

\begin{tabular}{cccc}
\hline Variables & Asians & Blacks & Whites \\
Female & -0.099 & 0.021 & -0.049 \\
Age & $(0.066)$ & $(0.051)$ & $(0.036)$ \\
& $-0.007^{* * *}$ & $0.007^{* * *}$ & $0.008^{* * *}$ \\
Incomplete Primary & $(0.003)$ & $(0.002)$ & $(0.002)$ \\
& -0.537 & 0.096 & $-0.246^{*}$ \\
Complete Primary & $(0.362)$ & $(0.091)$ & $(0.139)$ \\
Incomplete Tech Secondary & $-0.511^{* * *}$ & -0.068 & $-0.230^{*}$ \\
Complete Tech Secondary & $(0.183)$ & $(0.091)$ & $(0.133)$ \\
& -0.415 & -0.036 & $-0.309^{* *}$ \\
Incomplete Univ. Secondary & $(0.323)$ & $(0.101)$ & $(0.136)$ \\
Complete Univ. Secondary & $-0.498^{* * *}$ & 0.113 & $-0.336^{* * *}$ \\
Some University & $(0.184)$ & $(0.105)$ & $(0.13)$ \\
Complete University & $-0.706^{* * *}$ & -0.058 & $-0.236^{*}$ \\
& $(0.251)$ & $(0.112)$ & $(0.139)$ \\
& $-0.674^{* * *}$ & -0.055 & $-0.317^{* *}$
\end{tabular}


Table 8. Ologit regression controls: Employment per ethnic group dependent variable: Happiness.

\begin{tabular}{cccc}
\hline Variables & Asians & Blacks & Whites \\
\hline Part time & -0.117 & $0.435^{* * *}$ & 0.096 \\
& $(0.106)$ & $(0.114)$ & $(0.08)$ \\
Self Employed & 0.055 & $0.169^{* *}$ & -0.005 \\
& $(0.111)$ & $(0.082)$ & $(0.065)$ \\
Retired/Pensioned & 0.062 & -0.085 & -0.036 \\
& $(0.15)$ & $(0.135)$ & $(0.065)$ \\
Housewife not employed & -0.085 & -0.075 & $-0.168^{* *}$ \\
& $(0.103)$ & $(0.101)$ & $(0.072)$ \\
Student & -0.097 & 0.014 & $-0.201^{* *}$ \\
& $(0.13)$ & $(0.093)$ & $(0.09)$ \\
Unemployed & $0.425^{* *}$ & $0.286^{* * *}$ & $0.338^{* * *}$ \\
& $(0.203)$ & $(0.085)$ & $(0.083)$ \\
Other & -0.038 & $0.412^{*}$ & $0.230^{*}$ \\
& $(0.139)$ & $(0.227)$ & $(0.138)$ \\
\hline
\end{tabular}

Table 9. Ologit regression controls: Social class and income per ethnic group dependent variable: Happiness.

\begin{tabular}{|c|c|c|c|}
\hline Variables & Asians & Blacks & Whites \\
\hline \multirow[t]{2}{*}{ Upper middle class } & 0.107 & 0.308 & 0.217 \\
\hline & (0.339) & $(0.19)$ & (0.194) \\
\hline \multirow[t]{2}{*}{ Lower middle class } & 0.549 & $0.539^{* * * *}$ & $0.405^{* *}$ \\
\hline & $(0.34)$ & $(0.187)$ & $(0.196)$ \\
\hline \multirow[t]{2}{*}{ Working class } & $0.790^{* *}$ & $0.465^{* *}$ & $0.541^{* * *}$ \\
\hline & $(0.342)$ & $(0.189)$ & $(0.198)$ \\
\hline \multirow[t]{2}{*}{ Lower class } & $1.623^{* * *}$ & $0.817^{* * * *}$ & $1.053^{* * *}$ \\
\hline & $(0.364)$ & $(0.191)$ & $(0.211)$ \\
\hline \multirow[t]{2}{*}{ Second step } & $-0.369^{* *}$ & -0.079 & $-0.241^{* *}$ \\
\hline & $(0.161)$ & $(0.105)$ & $(0.1)$ \\
\hline \multirow[t]{2}{*}{ Third Step } & $-0.483^{* * *}$ & $-0.170^{*}$ & $-0.254^{* * *}$ \\
\hline & $(0.159)$ & $(0.099)$ & $(0.094)$ \\
\hline \multirow[t]{2}{*}{ Forth Step } & $-0.602^{* * *}$ & $-0.285^{* * *}$ & $-0.462^{* * *}$ \\
\hline & $(0.162)$ & $(0.099)$ & $(0.094)$ \\
\hline \multirow[t]{2}{*}{ Fifth Step } & $-0.849^{* * *}$ & $-0.446^{* * *}$ & $-0.669^{* * *}$ \\
\hline & $(0.153)$ & $(0.098)$ & $(0.092)$ \\
\hline \multirow[t]{2}{*}{ Sixth Step } & $-0.854^{* * *}$ & $-0.577^{* * *}$ & $-0.805^{* * *}$ \\
\hline & $(0.158)$ & $(0.106)$ & $(0.097)$ \\
\hline \multirow[t]{2}{*}{ Seventh Step } & $-0.854^{* * *}$ & $-0.618^{* * *}$ & $-0.837^{* * *}$ \\
\hline & $(0.175)$ & $(0.113)$ & $(0.1)$ \\
\hline \multirow[t]{2}{*}{ Eighth Step } & $-0.698^{* * *}$ & $-0.786^{* * *}$ & $-1.060^{* * *}$ \\
\hline & $(0.189)$ & $(0.13)$ & $(0.107)$ \\
\hline \multirow[t]{2}{*}{ Ninth Step } & $-0.807^{* * *}$ & $-0.690^{* * *}$ & $-0.991^{* * *}$ \\
\hline & $(0.23)$ & $(0.206)$ & $(0.127)$ \\
\hline \multirow[t]{2}{*}{ Upper Step } & $-0.641^{* *}$ & -0.308 & $-1.072^{* * *}$ \\
\hline & $(0.261)$ & $(0.212)$ & $(0.132)$ \\
\hline \multirow[t]{2}{*}{ Constant } & $-1.685^{* * *}$ & $-1.534^{*}$ & $-1.115^{* * *}$ \\
\hline & $(0.495)$ & $(0.82)$ & $(0.277)$ \\
\hline \multirow[t]{2}{*}{ Constant } & $1.633^{* * * *}$ & 0.737 & $1.968^{* * *}$ \\
\hline & $(0.494)$ & $(0.82)$ & $(0.277)$ \\
\hline \multirow[t]{2}{*}{ Constant } & $3.680^{* * * *}$ & $2.938^{* * * *}$ & $4.326^{* * *}$ \\
\hline & $(0.5)$ & $(0.822)$ & $(0.285)$ \\
\hline Observations & 4977 & 6524 & 13,407 \\
\hline
\end{tabular}

Robust standard errors in parentheses, ${ }^{* * *} \mathrm{p}<0.01,{ }^{* *} \mathrm{p}<0.05,{ }^{*} \mathrm{p}<0.1$. 


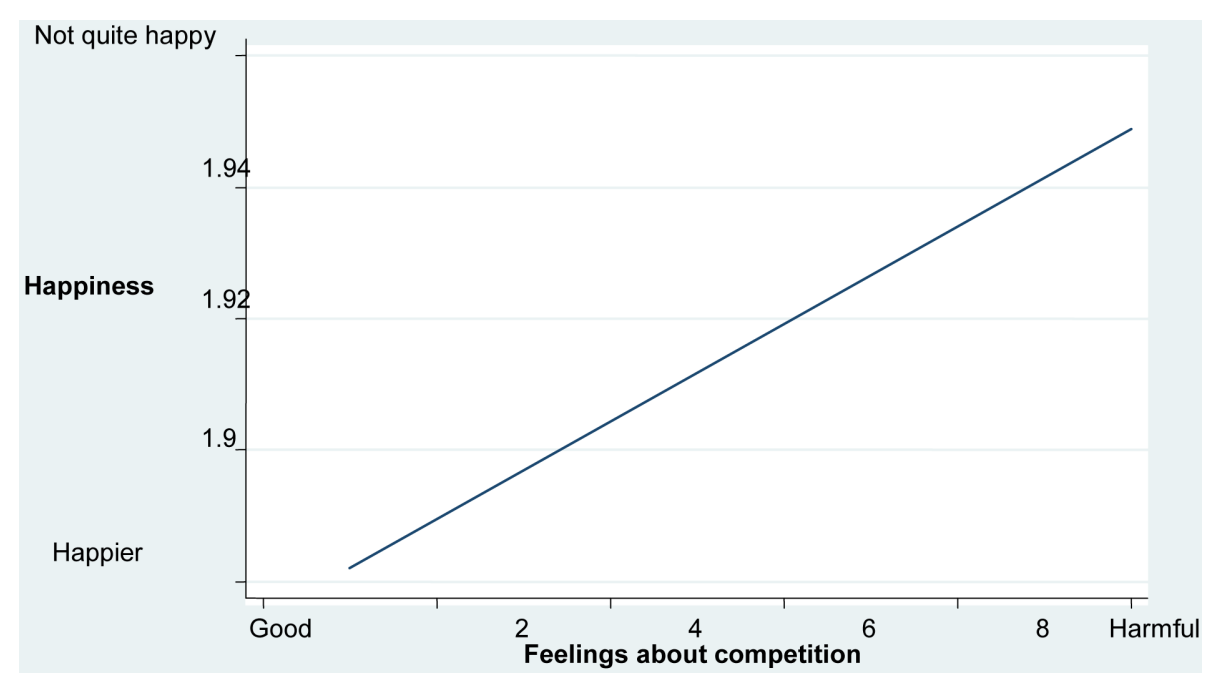

Figure 1. Correlation between competition and happiness.

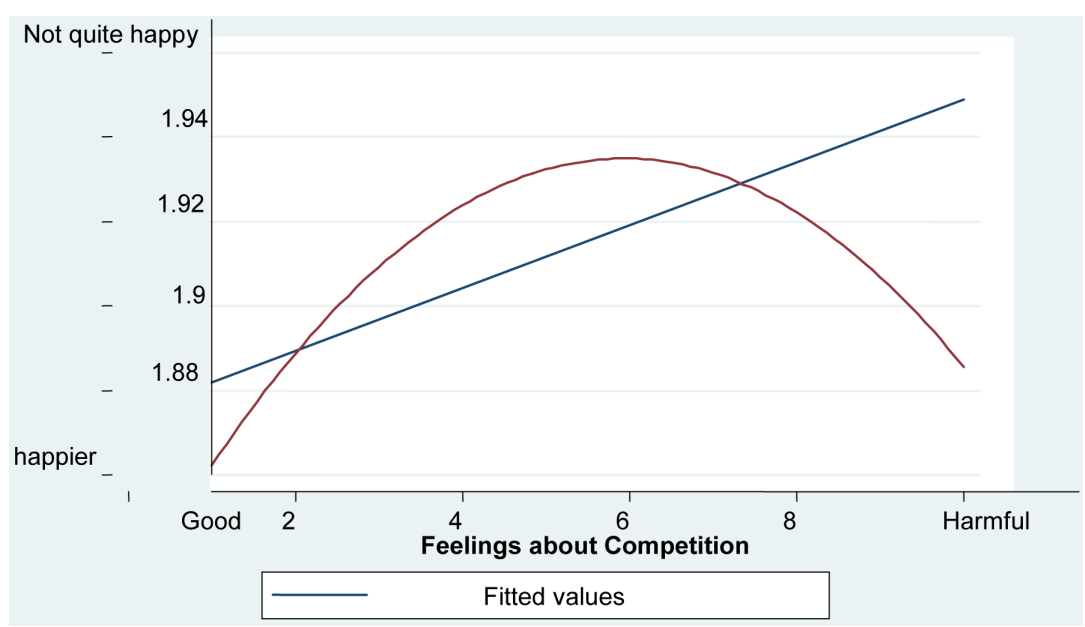

Figure 2. Feelings for competition and happiness.

happiness.

The central question of this paper deals with the potential differences between ethnic groups. First, for the first four categories, feelings about competition appear to affect happiness in a very similar way, except for Category 2 White individuals, who do not show statistical differences with category 1.

The most striking ethnic difference is observed in the case of Black individuals. Almost $40 \%$ of Black people located their answers between Category 5 and 10, meaning that 4 out of 10 of them think Competition is harmful or more harmful than good. Neither of these significantly differs with those who think competition is good with respect to their self-reported happiness. In other words, they are as happy as those who feel competition is a good thing. This result contrasts with those for Asians and Whites, the majority of which significantly differ with their most competitive-inclined colleagues on the effect over self-reported happiness.

Tables 7-9 show the effect of control variables. Across ethnic groups, females are not happier than men. Age however, appears to have a positive effect on happiness for Asians but a negative effect for Blacks and Whites, although the total effect seems small.

When it comes to the effect of education on happiness, there are significant differences between Blacks on one side and Asians and Whites on the other: education has a positive and significant effect on happiness for Whites and Asians, but it appears that more educated Blacks are not happier than their non-educated fellows. Finally, individuals earning more money are associated with increased happiness in line with previous literature [21] as well as individuals of higher social classes. 


\subsubsection{Marginal Effects}

Conclusions beyond simple trends require information about the marginal effects of competition on happiness. The results for each ethnic group are shown in Tables 10-12. Most of Asians and Whites (Tables 10-12) who increasingly dislike competition feel less happy. Those who really dislike competition, however, show similar levels of happiness than those who think competition is good. The marginal effects indicate that less competitive-inclined Asians are around 6\% to 8\% less happy than more competitive-inclined Asians. The figures for Whites are a bit different: they are around $4 \%$ to $7 \%$ less happy. Blacks (Table 11), however, are affected differently by competition: only those closer to more competitive-inclined individuals are significantly happier, but those who tend to think competition is harmful show no significant differences in self-reported happiness. Moreover, as we move down in the likeness of competition, individuals are marginally less happy: those closer to more competitive-inclined individuals increase their probability of being happy by more than $6 \%$ while those individuals in the third category increase that probability in only $5 \%$ and so on.

Table 10. Marginal effects of competition (MEMs) asian individuals dependent variable: Happiness.

\begin{tabular}{|c|c|c|c|}
\hline Variables & $\mathrm{dy} / \mathrm{dx}$ & $\mathrm{p}>\mathrm{z}$ & $\mathrm{X}$ \\
\hline Competition 2 & $\begin{array}{l}-0.060 \\
(0.015)^{*}\end{array}$ & 0.000 & 0.154 \\
\hline Competition 3 & $\begin{array}{c}-0.079 \\
(0.014)^{*}\end{array}$ & 0.000 & 0.195 \\
\hline Competition 4 & $\begin{array}{l}-0.065 \\
(0.014)^{*}\end{array}$ & 0.000 & 0.137 \\
\hline Competition 5 & $\begin{array}{l}-0.066 \\
(0.015)^{*}\end{array}$ & 0.000 & 0.173 \\
\hline Competition 6 & $\begin{array}{l}-0.086 \\
(0.015)^{*}\end{array}$ & 0.000 & 0.067 \\
\hline Competition 7 & $\begin{array}{l}-0.073 \\
(0.021)^{*}\end{array}$ & 0.001 & 0.041 \\
\hline Competition 8 & $\begin{array}{l}-0.078 \\
(0.021)^{*}\end{array}$ & 0.000 & 0.039 \\
\hline Competition 9 & $\begin{array}{l}-0.050 \\
(0.034)\end{array}$ & 0.138 & 0.016 \\
\hline Competition is harmful & $\begin{array}{l}-0.034 \\
(0.036)\end{array}$ & 0.339 & 0.018 \\
\hline
\end{tabular}

Robust standard errors in parentheses, ${ }^{* * *} \mathrm{p}<0.01,{ }^{* *} \mathrm{p}<0.05,{ }^{*} \mathrm{p}<0.1$.

Table 11. Marginal effects of competition (MEMs) black individuals dependent variable: Happiness.

\begin{tabular}{|c|c|c|c|}
\hline Variables & $\mathrm{dy} / \mathrm{dx}$ & $\mathrm{p}>\mathrm{z}$ & $\mathrm{X}$ \\
\hline Competition 2 & $\begin{array}{c}-0.064 \\
(0.015)^{*}\end{array}$ & 0.000 & 0.131 \\
\hline Competition 3 & $\begin{array}{c}-0.050 \\
(0.015)^{*}\end{array}$ & 0.001 & 0.106 \\
\hline Competition 4 & $\begin{array}{c}-0.056 \\
(0.015)^{*}\end{array}$ & 0.000 & 0.098 \\
\hline Competition 5 & $\begin{array}{c}-0.029 \\
(0.015)^{* * *}\end{array}$ & 0.056 & 0.136 \\
\hline Competition 6 & $\begin{array}{l}-0.014 \\
(0.019)\end{array}$ & 0.466 & 0.067 \\
\hline Competition 7 & $\begin{array}{l}-0.023 \\
(0.021)\end{array}$ & 0.276 & 0.046 \\
\hline Competition 8 & $\begin{array}{c}-0.007 \\
(0.023)\end{array}$ & 0.750 & 0.044 \\
\hline Competition 9 & $\begin{array}{l}-0.030 \\
(0.026)\end{array}$ & 0.247 & 0.030 \\
\hline Competition is harmful & $\begin{array}{c}0.0022 \\
(0.025)\end{array}$ & 0.930 & 0.055 \\
\hline
\end{tabular}

Robust standard errors in parentheses, ${ }^{* * *} \mathrm{p}<0.01,{ }^{* *} \mathrm{p}<0.05,{ }^{*} \mathrm{p}<0.1$. 
Table 12. Marginal effects of competition (MEMs) white individuals dependent variable: Happiness.

\begin{tabular}{|c|c|c|c|}
\hline Variables & $\mathrm{dy} / \mathrm{dx}$ & $\mathrm{p}>\mathrm{z}$ & $\mathrm{X}$ \\
\hline Competition 2 & $\begin{array}{l}-0.007 \\
(0.011)\end{array}$ & 0.528 & 0.136 \\
\hline Competition 3 & $\begin{array}{l}-0.056 \\
(0.009)^{*}\end{array}$ & 0.000 & 0.150 \\
\hline Competition 4 & $\begin{array}{l}-0.063 \\
(0.010)^{*}\end{array}$ & 0.000 & 0.131 \\
\hline Competition 5 & $\begin{array}{l}-0.040 \\
(0.010)^{*}\end{array}$ & 0.000 & 0.161 \\
\hline Competition 6 & $\begin{array}{l}-0.044 \\
(0.012)^{*}\end{array}$ & 0.000 & 0.069 \\
\hline Competition 7 & $\begin{array}{l}-0.030 \\
(0.014)^{* *}\end{array}$ & 0.042 & 0.048 \\
\hline Competition 8 & $\begin{array}{l}-0.058 \\
(0.014)^{*}\end{array}$ & 0.000 & 0.047 \\
\hline Competition 9 & $\begin{array}{l}-0.029 \\
(0.021)\end{array}$ & 0.169 & 0.026 \\
\hline Competition is harmful & $\begin{array}{l}-0.005 \\
(0.020)\end{array}$ & 0.805 & 0.036 \\
\hline
\end{tabular}

In sum, there are differences between Whites and Asians with respect to Blacks in the way feelings about competition affect their self-reported happiness. It appears that, somewhat, blacks individuals who dislike competition may shy away from it, findings new ways for being happy (more below).

Besides the difference in the effect of competition on happiness for different ethnic groups, these findings show differences with those observed by Fischer (2008), who reports a positive relation between competition and happiness but does not report a nonlinear relation among the variables. Moreover, her study does not analyze a direct relation between competition and happiness (more below).

The general findings of this paper also are different with those of Brandts et al. who report a negative relation between competition and happiness (at least for some parties involved in the transaction). Although the general conclusion of this paper stands for a positive association between competition and happiness, there are some significant negative correlations too, since, as noted above, individuals with greater aversion to competition report higher levels of happiness.

In sum, this paper's results challenge the mainstream view that competition is always a good thing and also show preliminary results that competition may have different effects on happiness for different ethnic groups, in this case, black individuals. Also, these findings give support for an alternative view that people may feel happier with less competition, probably because they view competition is a harmful process where a few winners win at the expense of a majority of losers, hurts the environment and produce inefficient results.

\subsection{Robustness (for the General Case)}

The analysis so far has ignored issues of endogenous independent variables. In the econometric model outlined above, OLS estimation assumes that the regressors are uncorrelated with the error in the model, which means assuming that the only effect of the explanatory variables on happiness is a direct effect which is measured by the respective coefficients. In other words, there is no effect of competition on happiness that may go through the error term.

It happens, however, that one can argue that the association between feelings about competition and happiness is a two-way relation: those who like competition more tend to be happier individuals or, the other way around, happier individuals tend to view competition as a good thing rather than a bad thing. Or, we could also argue that there are omitted variables which operate through the error term but which also directly affect happiness and feelings about competition.

One way to address the issue of endogenous independent variables is by using instrumental variables, that is, variables that are correlated with the explanatory variable of interest (here, feelings about competition) but not 
correlated with the error term.

In this study, the opinions of individuals about the importance of hard work to achieving a better life and being a successful person are used as instrument for feelings about competition. Specifically, the variable is built from answers to the following question: "How would you place your views on this scale? 1 means you agree completely with the statement on the left; 10 means you agree completely with the statement on the right; and if your views fall somewhere in between, you can choose any number in between (Table 13):

The intuition behind the relation between hard effort and feelings about competition appears to be straightforward: individuals who think working hard will bring a better life would presumably be the ones who like competition more, or are more competitive, while those who think success is a matter of luck and connections, most probably should think that competition is not such a good thing. We then should observe a positive and relatively high correlation of feelings about competition and the effectiveness of hard work for achieving a better life. In fact, the pairwise correlation between the two is positive and relatively high: 0.35 .

On the other hand, hard work and happiness need not be correlated. There is no a priori economic reason to conclude that a person who thinks hard work is conducive to a better life would, at the same time, be happier than a person who thinks that success is a matter of connections. One way to rationalize this non-relation is by noting that success may not be equivalent to happiness, due to the elusive meaning of what we mean by success. If this intuition is accepted, we should observe a very low correlation between hard work and happiness, which, in fact, is what the data shows, a positive but low correlation of 0.0495 .

Table 14 shows the average results for hard work for each category of self-reported happiness.

As we can note from the table above, there are no significant differences in the means of what people think about hard work across self-reported happiness.

A two stage least square regression is run using hard work as instrumental variable. Weaknesses of the instrument as well as its relevance are tested. The identification test measured by the Cragg-Donald (N-L)*min Eval/L2F-Stat equals 41.5, greater than the critical value of 11, this rejecting the null hypothesis of a weak instrument. The identification/IV relevance test (measure by the Anderson-Cannon correlation LR statistic of 10.304) also rejects the null of an irrelevant instrument.

Using hard work as an instrument for feelings about competition gives similar results, suggesting that feelings about competition has a causal effect on happiness: individuals who think competition is good tend to be happier than those individuals who think competition is harmful. Table 15 shows the regression results.

This method to approximate a causal relation between competition and happiness, although with limitations, improves over other studies, specifically Fischer (2008). Fisher's study analyzes the effect of competition on happiness and concludes that this effect is mediated by the bargaining position of each individual, measured by her income level. Fisher uses instrumental variables to explore the causality between competition and happiness but she looks at attitudes with respect to past and current effort to instrument income but not competition. As a consequence, the problem of reverse causality between happiness and competition is not addressed, but instead that of income and happiness, which is not the focus of her study (Table 15).

\subsection{Competition and Happiness among Blacks within Countries}

The suggestion that there may not be a clear association between feelings about competition and self-reported happiness among blacks ("probably because they are not the winners in the competitive process of capitalism") deserves closer scrutiny. Since regressions report average effects, the association between competition and happiness may be different for black individuals in different countries.

In other words, although the regressions above control for country-fix effects, one may nevertheless speculate about whether self-reported happiness of blacks who feel competition is harmful is statistically similar to selfreported happiness of competition-fan blacks within different countries. To investigate this matter, five countries are selected for which the number of black individuals surveyed allows for an appropriate econometric analysis. Results of the o-logit regressions are presented in Table 16.

In general, results confirm the conclusions above: in three of the five selected countries black individuals who think competition is good are as happy as those who increasingly dislike competition. Although it confirms the general pattern, the situation is slightly different in Brazil where results show some statistically significant differences in some cases, probably because the number of black individuals surveyed is small. Although Zambia appears as an outsider (that is individuals who think competition is harmful significantly reveal different levels 
Table 13. Opinions about hard work world value surveys.

\begin{tabular}{|c|c|c|c|c|c|c|c|c|}
\hline $\begin{array}{l}\text { In the long run, hard work } \\
\text { usually brings a better life }\end{array}$ & & & & & & & & $\begin{array}{l}\text { Hard work doesn't generally bring success- } \\
\text { it's more a matter of luck and connections }\end{array}$ \\
\hline 1 & 22 & 33 & 44 & 55 & 66 & 77 & 99 & 10 \\
\hline
\end{tabular}

Table 14. Self reported happiness and opinions on hard work.

\begin{tabular}{ccccc}
\hline Over & Mean & Std. Err. & [95\% Conf. & Interval] \\
\hline Hard-work & & & & 3.96 \\
_Very Happy & 4.00 & 0.020 & 4.24 & 4.04 \\
_Quite Happy & 4.27 & 0.014 & 4.31 & 4.43 \\
_Not very Happy & 4.37 & 0.030 & 4.39 & 4.70 \\
_Not at all Happy & 4.54 & 0.078 & & \\
\hline
\end{tabular}

Table 15. Effect of feelings about competition on self reported happiness instrumental variable. Hard work.

\begin{tabular}{ccccccc}
\hline happiness & Robust Coef. & Std. Err. & $\mathrm{Z}$ & $>\mathrm{z}$ & [95\% Conf. & Interval] \\
\hline Competition & 0.595 & 0.225 & 2.64 & 0.008 & 0.154 & 1.037 \\
Female & -0.177 & 0.060 & -2.94 & 0.003 & -0.295 & -0.059 \\
Age & 0.002 & 0.0006 & 0.64 & 0.000 & 0.001 & 0.003 \\
Education & 0.045 & 0.014 & 0.18 & 0.001 & 0.017 & 0.072 \\
Employment & 0.018 & 0.005 & 0.63 & 0.000 & 0.008 & 0.028 \\
Social class & 0.044 & 0.019 & 0.31 & 0.021 & 0.006 & 0.081 \\
Income & -0.057 & 0.006 & 8.92 & 0.000 & -0.070 & -0.044 \\
Country & 0.001 & 0.000 & 0.25 & 0.000 & 0.001 & 0.002 \\
_cons & -0.479 & 0.803 & 0.60 & 0.551 & -2.053 & 1.094 \\
\hline
\end{tabular}

Observations: 41,228; F $(8,41,219)=63.27$ Prob > F = 0.0000 .

Table 16. Ologit regression effect of competition black individuals selected countries dependent variable: Happiness.

\begin{tabular}{|c|c|c|c|c|c|}
\hline \multirow{2}{*}{ Variables } & \multicolumn{5}{|c|}{ COUNTRIES } \\
\hline & Brazil & B. Faso & Mali & Rwanda & Zambia \\
\hline \multirow[t]{2}{*}{ Competition 2} & 1.002 & -0.051 & 0.057 & 0.019 & $0.483^{* *}$ \\
\hline & $(1.02)$ & $(0.242)$ & $(0.243)$ & $(0.301)$ & $(0.204)$ \\
\hline \multirow[t]{2}{*}{ Competition 3} & -0.043 & 0.076 & -0.22 & -0.005 & $0.562^{* *}$ \\
\hline & $(0.898)$ & $(0.24)$ & $(0.264)$ & $(0.321)$ & $(0.219)$ \\
\hline \multirow[t]{2}{*}{ Competition 4} & $2.439^{* *}$ & 0.121 & -0.279 & $-0.528^{*}$ & $1.098^{* * *}$ \\
\hline & (1.065) & $(0.196)$ & $(0.26)$ & $(0.318)$ & (0.249) \\
\hline \multirow[t]{2}{*}{ Competition 5} & -0.867 & 0.155 & -0.075 & -0.121 & $0.651^{* *}$ \\
\hline & $(0.721)$ & (0.199) & $(0.213)$ & $(0.301)$ & $(0.296)$ \\
\hline \multirow[t]{2}{*}{ Competition 6} & -0.657 & -0.369 & -0.61 & 0.300 & 0.416 \\
\hline & $(0.896)$ & $(0.267)$ & $(0.433)$ & $(0.336)$ & $(0.301)$ \\
\hline \multirow[t]{2}{*}{ Competition 7} & $-1.706^{*}$ & 0.061 & -0.700 & 0.013 & $0.861^{* * *}$ \\
\hline & (1.006) & $(0.296)$ & $(0.515)$ & $(0.332)$ & $(0.284)$ \\
\hline \multirow[t]{2}{*}{ Competition 8} & -0.193 & 0.154 & -0.367 & 0.447 & $0.535^{*}$ \\
\hline & (1.327) & (0.369) & (0.373) & $(0.426)$ & $(0.311)$ \\
\hline \multirow[t]{2}{*}{ Competition 9} & 0.16 & 0.393 & -0.424 & $0.622^{*}$ & $0.915^{* * *}$ \\
\hline & $(0.984)$ & $(0.437)$ & $(0.437)$ & $(0.362)$ & $(0.337)$ \\
\hline \multirow[t]{2}{*}{ Competition 10 (harmful) } & -0.665 & 0.162 & -0.046 & -0.194 & $0.527^{*}$ \\
\hline & $(0.79)$ & $(0.486)$ & $(0.254)$ & $(0.805)$ & $(0.315)$ \\
\hline Observations & 128 & 1020 & 822 & 998 & 979 \\
\hline
\end{tabular}

Robust standard errors in parentheses; ${ }^{* * *} \mathrm{p}<0.01,{ }^{* *} \mathrm{p}<0.05,{ }^{*} \mathrm{p}<0.1$; Other explanatory variables are omitted. 
of happiness than those who think competition is good), the general positive association is confirmed: individuals who have less favorable views about competition are associated with lower self-reported happiness.

\section{Discussion}

This paper investigates the relation between competition and happiness and gauges if feelings about competition have different effects on happiness for three different ethnic groups, Whites, Blacks, and Asians. Individual measures of feelings about competition and self-reported happiness are derived from the WVS. This gives a direct link between the two variables, which contrasts with Fischer (2008) who studies the effect of an aggregated measured of competition (the KOF index) on happiness mainly through the relation between competition and income. On the general relation between feelings about competition and happiness, a direct negative relation is not found. Nevertheless, people with higher aversion to competition report lower levels of happiness, suggesting that competition may be exerting negative effects on individuals.

This may be in line with the findings of Brandts et al. (2005) in their experiments with players, who suggest that under certain institutional environments, players experience negative emotions when competition rises, possible due to higher "social stress".

When different ethnic groups are considered, significant differences between Blacks and the two other groups arise. Both Whites and Asians show a positive but decreasing marginal relation between competition and happiness for almost all individuals, while Blacks appear to shy away from competition and even show a negative relation for those who find competition is harmful, that is, they are happier than those blacks who have a positive view about competition, although, the effect is not statistically significant. When different countries are considered, no statistically significant differences in self-reported happiness are found, except for Zambia.

One reason for this finding (of the negative relation in individuals with high aversion to competition) may be that the view of competition expressed by individuals may differ from the notion of competition addressed by economists. Mainstream economists have long considered competition as an "end-state", a situation characterized by equilibrium in which efficient outcomes (in production and consumption) have been achieved. This view implies the practical notion that voluntary trading through competition drives inefficient firms out of the market, thus a good thing.

On the other hand, competition may be regarded as a dynamic "process" where producers rival with each other to obtain a larger share of the pie, and in which efficient outcomes are not always achieved ${ }^{17}$. This positive but decreasing relationship between competition and happiness may well be describing both of those views about competition. This is true especially for black individuals, as mentioned above.

The results shown in this paper, both for the general case and for the analysis of different ethnic groups can be considered robust to different institutional factors, since country fixed effects are controlled for, partially addressing Fischer's (2008) concerns about the potential effects of institutional environments and the nature of contracts, which are the fundamental assumptions the (economic) theoretical view of competition makes and which may drive the well known results on efficiency and wellbeing: that preferences are independent of the institutional environment and that complete contracts are perfectly enforceable.

In general terms, the findings of this work are consistent with the opinion of economic historian Marc Blaug, a strong supporter of the so called "process-view" of competitive capitalism:

The man-in-the-street favours capitalism because it is ultimately responsive to consumers' demands, technologically dynamic and produces the goods that are wanted at low cost; of course, it also suffers from periodic slumps, more or less chronic unemployment even in booms, and frequently generates a highlyunequal distribution of income. Still, on balance the good outweighs the bad and without becoming Panglossian, he or she votes for capitalism — and so do virtually all economists.

Moreover, Cornell's Economist Robert Frank [22] argues that the appropriate view of competition should be the one based on Darwin's principles rather than on Adam Smith's lines. Essentially Smith argues that competition reveals good for society although each individual pursues only his own, limited interests. Darwin's natural selection process argues that competition selects those who are more fit to it. The basic difference relies on the potential contradiction between individual and social outcomes: while competition may prove satisfactory for a few winners, it may result in frustration for a vast majority, the losers. Theoretically, mainstream economists

\footnotetext{
${ }^{17}$ For a lucid review of both views, see Blaug (2001).
} 
have solved this potential problem by postulating appropriate compensations from the winners to the losers. Anyways, followers of Smith argue that there is no contradiction, while Darwinists support the opposite view ${ }^{18}$.

Frank's opinion is useful to understand the different effect for different ethnic groups in terms of who is favored and who is not by competition. Blacks appear to be the less favored group in competitive environments, which may force them to find other ways of interaction within the capitalist system to achieve higher levels of happiness. Of course, this is speculative and difficult to prove within the domain of Economics.

In other words, although positive views about competition are generally associated with higher levels of selfreported happiness, individuals with different opinions about competition report similar levels of happiness. As noted, however, the result that individuals who really dislike competition report a higher level of happiness is somewhat puzzling and somehow contradicts Blaug's quote above. One could conjecture about the behavior of individuals who increasingly dislike competition: because they see competition as a bad thing or because they have experienced the bad things about competition, they may shy away from it and may choose to live and work in less competitive environments, thus achieving a higher level of happiness. This conclusion may be consistent with the "process-view" of competition, where competition is regarded as a conflict between companies or persons to achieve a specific goal. On the other hand, too much competition may lead to situations where people are hurt in their self esteem and are prisoners of jealously to other persons' success [23].

In addition, however, the findings of this paper suggest in general that the pessimistic view of competition expressed by researchers outside the economic profession may be overstated, e.g. Kohn [6]. Maybe what is driving these pessimistic results is the fact that their evidence relies on experiments on cooperative behavior where the subjects are only children, suggesting that competition affect only adults and not children. Competition may indeed be one of the factors that make behavior of adults significantly different that the behavior of children, but not just the only one. What Kohn shows is not that competition is necessarily bad, but that adult behavior is different than child behavior in relation to cooperation, which appears to be a different issue. Moreover, experimental studies on trust and ultimatum games show that individuals trust and cooperate more than what is assumed by economic theory [24] [25].

In sum, competition appears to be associated with higher levels of happiness, but may cause more harm than good to many people, as some studies in the field of Psychology suggest and as I suggest in this paper for the case of Black individuals.

This study has limitations, one of which is the analysis of causality, partially addressed here. A more profound study of the appropriate instrument is called for. Another limitation has to do with my measure of competition: competition is defined based on subjective opinions about it, which may not represent the competitive environment of the location where the individual lives. This issue is partially addressed by the inclusion of country fixed effects in the regressions, but a more direct measure of the competitive environment would be a nice improvement to the paper.

Another improvement to this paper could be to better define ethnicity. Asians, Whites and Blacks represent three different groups of people, but ethnicity also has to do with religion, beliefs, norms and attitudes. How different people in different parts of the world react to competition is, probably, a key issue to understand the functioning of capitalism and to assess its future, its potentials and problems.

Another fruitful extension of this paper would be to examine what differences exist among African countries (and others) as the analysis here suggests different consequences on happiness.

The policy implications of this paper are tentative. On the one side, happier persons like competition more, but persons with the same level of happiness reject it as harmful. Competition may lead to a "race to the bottom" situation, where only some corporate interests are benefited, while the general public may not. Rough competition in the so-called labor market, both inside and outside firms, hurt rather than benefit workers, for example.

Since competition cannot be avoided in capitalistic societies, governments can actually manage institutional structures, as Fischer (2006) suggests. But the effect of competition may run deeper and better institutional environments may not suffice.

\section{References}

[1] Bjørnskov, C.B., Dreher, A. and Fischer, J.A.V. (2008) On Decentralization and Life Satisfaction. Economics Letters, 99, 147-151.

\footnotetext{
${ }^{18}$ In fact, Smith’s view of competition may be closer to Darwin’s than Frank suggests (see Blaug, 2001).
} 
[2] Guiso, L., Sapienza, P. and Zingales, L. (2006) Does Culture Affect Economic Outcomes? Journal of Economic Perspectives, 20, 23-48. http://dx.doi.org/10.1257/jep.20.2.23

[3] World Value Surveys. www.worldvaluessurvey.org

[4] Diener, E. (1984) Subjective Wellbeing. Psychological Bulleting, 95, 542-575. http://dx.doi.org/10.1037/0033-2909.95.3.542

[5] Triandis, H.C. (2000) Cultural Syndromes and Subjective Well-Being. In: Diener, E. and Suh, E.M., Eds., Culture and Subjective Well-Being, The MIT Press, Cambridge, MA, 13-36.

[6] Kohn, A. (1992) No Contest: The Case against Competition. Revised Edition, Houghton Mifflin Company, Boston, New York.

[7] Brandts, J., Riedl, A. and van Winden, F. (2005) Competition and Well-Being. IZA Discussion Papers 1769.

[8] Liebrand, W.B.G. (1984) The Effect of Social Motives, Communication and Group Size on Behavior in an n-Person Multi-Stage Mixed Motive Game. European Journal of Social Psychology, 14, 239-264. http://dx.doi.org/10.1002/ejsp.2420140302

[9] Stigler, G. (1987) In the New Palgrave. In: Eatwell, J., Milgate, M. and Newman, P., Eds., The New Palgrave. A Dictionary of Economics, The MacMillan Press Limited, London, 531-535.

[10] Fischer, J.A.V. (2008) Competition and Well-Being: Does Market Competition Make People Unhappy. SSE/EFI Working Paper Series in Economics and Finance, No. 697.

[11] Helliwell, J.F., Huang, H.F. and Wang, S. (2013) Social Capital and Well-Being in Times of Crisis. Journal of Happiness Studies, 15, 145-162. http://dx.doi.org/10.1007/s10902-013-9441-z

[12] Suh, E.M. and Oishi, S. (2002) Subjective Well-Being across Cultures. On line readings on Psychology and Culture, 10(1).

[13] Biswas-Diener, R., Vitterso, J. and Diener, E. (2005) Most People Are Pretty Happy, But There Is Cultural Variation: The Inughuit, the Amish, and the Maasai. Journal of Happiness Studies, 6, 205-226 http://dx.doi.org/10.1007/s10902-005-5683-8

[14] KOF Index of Globalization. http://globalization.kof.ethz.ch/

[15] Blaug, M. (2001) Is Competition Such a Good Thing? Static Efficiency versus Dynamic Efficiency. Review of Industrial Organization, 19, 37-48. http://dx.doi.org/10.1023/A:1011160622792

[16] Hahnel, R. (2011) Green Economics: Confronting the Ecological Crisis. M.E. Sharpe, Armonk.

[17] Di Tella, R., MacCulloch, R.J. and Oswald, A.J. (2001) Preferences over Inflation and Unemployment: Evidence from Surveys of Happiness. American Economic Review, 91, 335-341. http://dx.doi.org/10.1257/aer.91.1.335

[18] Bruno, F. and Stutzer, A. (2002) What Can Economists Learn from Happiness Research? Journal of Economic Literature, 40, 402-435. http://dx.doi.org/10.1257/jel.40.2.402

[19] Richard, E. (1974) Does Economic Growth Improve the Human Lot? Some Empirical Evidence. In: David, P.A. and Reder, M.W., Eds., Nations and Households in Economic Growth: Essays in Honor of Moses Abramovitz, Academic Press, New York, 89-125. http://dx.doi.org/10.1016/b978-0-12-205050-3.50008-7

[20] Kenneth, T. (2009) Discrete Choice Methods with Simulation. 2nd Edition, Cambridge University Press, Cambridge. http://dx.doi.org/10.1017/cbo9780511805271

[21] Ferrer-i-Carbonell, A. (2005) Income and Well-Being: An Empirical Analysis of the Comparison Income Effect. Journal of Public Economics, 89, 997-1019. http://dx.doi.org/10.1016/j.jpubeco.2004.06.003

[22] Frank, R.H. (2011) The Darwin Economy: Liberty, Competition and the Common Good. Princeton University Press, Princeton.

[23] Boehm, J.K. and Sonja, L. (2008) Does Happiness Promote Career Success? Journal of Career Assessment, 16, 101116. http://dx.doi.org/10.1177/1069072707308140

[24] Cárdenas, J.C., Chong, A.E. and Ñopo, H.R. (2008) To What Extent Do Latin-Americans Trust and Cooperate? Field Experiments on Social Exclusion in Six Latin American Countries. Inter-American Development Bank, Research Department, Working Paper 635.

[25] Cárdenas, J.C., Chong, A.E. and Ñopo, H.R. (2008) Stated Social Behavior and Revealed Actions: Evidence from Six Latin American Countries Using Representative Samples. Inter-American Development Bank, Research Department, Working Paper 634. 